\title{
Feeding the Communal Family: "Family Time" and the Division of Household Labor in Cohousing
}

\author{
Heather Sullivan-Catlin \\ State University of New York at Potsdam
}

* Please address correspondence to Dr. Heather Sullivan-Catlin, SUNY Potsdam, Satterlee Hall 316-1, 44 Pierrepont Avenue, NY 13676. E-mail: sullivha@potsdam.edu.

\begin{abstract}
Cohousing communities are cooperative neighborhoods where privately-owned, individual households are clustered around a "common house" with shared facilities including a dining room for "common meals." This paper examines the tension between community and family in one cohousing community and analyzes the extent to which communalizing meals helps balance household labor by gender. The findings suggest that communalizing meals has a great deal of potential for addressing both the volume and distribution of household labor for cohousing families as well as those living in mainstream housing.
\end{abstract}

Gathering around the family dinner table is a strongly-held value in American culture (Kremer-Sadlik, Fatigante, and Fasulo, 2008) and many positive effects of family meals have been documented in the literature (Davidson and Gauthier, 2010). At the same time, expectations about family dinner can exacerbate the pressure on dual-career couples already in a "time bind" (Hochschild, 1997), and add stress to their marriages as women, especially working mothers, are more likely to feel overwhelmed by and unappreciated for these labors (Spitze and Loscocco, 2000). Yet most families, with some variation based on family structure and resources, mother's employment, and family functioning, do make time to eat together (Davidson and Gauthier, 2010). However, the quantity of time spent at the family dinner table has been in steady decline (Schor, 2005) despite its significance as a key activity for "family time" (Gutierrez, Price, and Arnould, 2008).

The notion of family time is closely related to the concept of "quality time," both of which have received increased attention in response to the extensive growth in labor force participation among middle-class mothers (DeVault 2000). This attention couples concern that parents are not spending enough time with their children, with a romanticized vision of the past and an idealized image of the family (Kremer-Sadlik et al, 2008) where family meals are 
"cast as positive experiences central to family preservation" (Price, 2008, p. 189). In addition, the cultural pressure to achieve idealized experiences of quality time can add to family stress (Kremer-Sadlik and Paugh, 2007) and the reality of family dinner may more closely resemble a "6 o'clock crash" (Larson and Richards, 1994), fraught with conflict and fatigue (Gutierrez et al, 2008). Through an examination of communal meals in cohousing, a form of intentional community, this article explores the tension between the notion of the family dinner as family time and the opportunity for redistributing, and balancing by gender, mealtime household labor.

Cohousing communities are resident-developed and managed cooperative neighborhoods where privately-owned (or less often, rented), self-sufficient household units are clustered around a "common house" with shared facilities including a dining room for "common meals" and assorted other amenities such as a children's play area, teen room, laundry, exercise space, and/or guest rooms (McCamant and Durrett, 1994; Meltzer, 2005). They typically range in size from fifteen to forty household units. Cohousing, a Danish model, was introduced in the United States in 1988 and has grown rapidly. Today there are over 100 established (i.e. built and occupied) cohousing communities in the United States and more on the way with over 100 other groups working on new projects. ${ }^{i}$

The common house is the heart of the community where members come together to dine, share childcare, socialize, and hold meetings. Each home is selfsufficient with a complete kitchen, but many evenings community dinners are available in the common house with residents taking turns at cooking and cleanup. Common dinners play a significant role in attracting people to cohousing. "Cohousers" cite both social (e.g. friendship, sense of community) and instrumental (e.g. reducing individual household labor, balancing the gendered division of household labor) functions of common meals as motivations for pursuing a cohousing lifestyle. This article will: 1 ) explore the extent to which these expectations regarding common meals are realized, 2) examine the related tension between community participation and family time in one cohousing community, and 3) analyze the extent to which communalizing meals helps redistribute and balance household labor by gender.

\section{Social and Instrumental Functions of Communal Life}

Above all, people live in cohousing because they want to live with others who are also intentionally choosing to live in community. Despite this common desire, they often identify different priorities for doing so (Sullivan-Catlin, 2004). For example, some are interested in the companionship or security of knowing their neighbors well, while others are motivated by the opportunity to live more sustainably by sharing resources or to receive help with the labors of daily life (e.g. cooking, cleaning, childcare, etc.).

These differing motivational priorities are consistent with Ahrentzen's (1996) conceptualization of shared space in housing. She outlines three types of sharing and their functions: 1) Co-presence: diminishes feelings of isolation; develops a sense of community and facilitates security; establishes social identity; 2) Affiliation (social-oriented interaction): companionship; social support; 
learning and growth; and, 3) Instrumental (task-oriented interaction): increases the number of amenities one can have within financial limitations; eases the individual's time and efforts in domestic and child care responsibilities (Ahrentzen, 1996, p. 50).

Due to their similarity and overlapping attributes I combine the first two types, co-presence and affiliation, into a single "social" category. The social and instrumental functions of cohousing are epitomized in the practice of common meals, an examination of which reveals gender, household labor, and family life issues.

\section{Feeding the Family: Gender, Meals, and the Division of Household Labor}

In her classic work, DeVault revealed that "feeding the family" goes well beyond putting food on the table: "Clearly, occasions of eating together produce sociability and connection in household groups. The satisfactions of participating in everyday ritual and indulging personal tastes can produce companionship, comfort, and security for both children and adults." She then went on to document how family meals "bundle these satisfactions together with the subordination of wives and mothers: too often they depend on women's shouldering the burden of their production, and often on women's sacrificing their own satisfaction for that of others" (1991, p. 236).

Though men's contribution to household labor has been increasing steadily over the past few decades, women still do the majority of this work (Sullivan, 2010). Meals are a significant source of household labor. They happen every day (as opposed to general cleaning or laundry, for example), often multiple times, though dinner is generally the most labor- and time-intensive. Feeding families involves numerous tasks - menu planning, shopping (or other provisioning such as gardening), preparation, serving, feeding small children (if present), and cleaning up. In Feeding the Family and other work DeVault cites the invisibility of many of these tasks as a cause of women's ongoing disproportionate share of this labor $(1991,1997)$. Indeed, feminist geographers and others have suggested that domestic architecture itself must be changed - the home must be "degendered" - and they call for housing and community design that reinforce shared space and domestic tasks (Spain, 1992, p. 235-236). However, moves toward communal dining, or any meals taken outside of the home, have been identified by some as a threat to the institutions of marriage and family (Neuhas, 2001).

According to Neuhaus, "the meaning of cooking for the family has intensified" (2001, p. 100-101). Over the past century American culture has "bound women, food, and love together" (Parkin, 2001, p. 52). As more women left the home for domestic employment, pressure on them mounted to fulfill both roles in a society where "filled cookie jars [are] symbols of motherly affection" (Endrijonas, 2001, p.163). DeVault argues that "since feeding work is associated so strongly with women's love and caring for their families, it is quite difficult for women to resist doing all of the work" (1997, p. 191). She concludes that "in addition to its constructive, affiliative aspect, the work of care - as presently organized- has a darker aspect, which traps many husbands and wives in relations 
of dominance and subordination rather than mutual service and assistance" (1997, p. 196). Inness suggests that this "complex web of interrelationships among women, food, and cooking must be untangled" (2001, p. 3). Efforts toward communal dining among cohousers help provide some insight into these issues.

\section{Communal Dining in Practice: The Case of Cohousing}

As early as 1898 feminists like Charlotte Perkins Gilman argued that work in the home should be minimized by bringing it into the public sphere where people would live in stripped down houses of living quarters supplemented by community laundries, eating, and child care facilities (Daniels, 1987). Over time others have proposed similar solutions, but the privacy and independence of the nuclear family remains a strongly held value, a formidable obstacle to implementing such strategies (Bose, 1979; Laslett, 1973). Yet, small segments of the population have "experimented" with alternatives such as communal living (Hayden, 1984; Laslett, 1973). The cohousing movement represents one of these alternatives, one that expressly seeks a balance between the more communal extreme of Gilman's vision and similar models at one end, and the relative isolation of the contemporary nuclear family at the other (Sullivan-Catlin, 2004).

One of the central features of cohousing is the common meal, usually dinner. In fact, this feature is often cited as a primary motive for living in cohousing and common houses are designed primarily for this purpose. A large kitchen and dining room designed to accommodate all of the residents can be found in the common houses of most of the 100 or so cohousing communities across the country. Common dinners are held two to five nights a week, varying from community to community. Each adult member of the community who participates in these dinners is expected to take a turn at preparation and clean-up, both of which are typically organized through some sort of committee or team system. Depending on the number of households in the community, this responsibility may fall on an individual only once or twice a month.

Cohousers expect common dinners to meet both social and instrumental needs by providing opportunities for socializing and freeing them from a significant portion of daily household labor. Whether they actually do is an issue that will be examined in the following comparison of the specific expectations and realities of how common meals are carried out in cohousing. This comparison will focus on the tension between the notion of the family dinner as family time and the opportunity for redistributing, and balancing by gender, mealtime household labor.

\section{The Study}

This research is based primarily on qualitative interviews with fifty members of the cohousing movement in the northeast region of the U.S.: thirty residents of an established community, Kindred Cohousing, and twenty members of a group in the process of developing a cohousing community, the Four Seasons Cohousing Group. ${ }^{\text {ii }}$ A semi-structured interview format was employed to allow for the maximum in detailed description, depth and validity (Reinharz 1992; Weiss 1994). The interviews addressed 1) motivations for involvement 
in cohousing, 2) household division of labor, and 3) the expectations for and, in the case of the Kindred Cohousing Community, the realities of cohousing life. Interviews were held in respondents' homes, typically at the kitchen table or in the living room. Most respondents arranged to be home alone in order to limit distractions. The particular respondent determined the course and length of each interview, ranging from forty-five minutes to over two hours, with most lasting approximately sixty to ninety minutes. Each interview was recorded and then transcribed. Sociodemographic information was gathered at the end of each interview with an open-response form. Here is a brief profile of the sample.

\section{Four Seasons Cohousing Group}

Eleven women and nine men participated in interviews representing all of the currently active members of the group as well as some former members who had left the group for a variety of reasons, most related to residential relocation. Among the twenty were eight couples who were either married (seven) or cohabiting (one). With regard to children, three were "empty nesters," six had no children and the remaining eleven had either one or two children at home.

\section{Kindred Cohousing Community}

A snowball sample of seventeen women and thirteen men participated in interviews (out of a total of thirty women and twenty men living in the community). Among the thirty were eight couples who were either married (seven) or cohabiting (one). With regard to children, two were empty nesters, three had no children and the remaining twenty-five had either one or two children at home. This sample of Kindred cohousers appears to be a fairly good representation of the community as a whole in terms of including singles and couples, people with children and without, full-time homemakers and employed women, those who work in home-based businesses or are self-employed, as well as a variety of ages and occupations.

\section{Overall Sample}

All interviewees identified as white with one specifying his identity as white Latino. At the time of the interviews two were in their 20s, thirty-eight were in their thirties or forties, and ten were over fifty years of age. As noted above, most of the interviewees were couples, but seven were single/never-married and five were divorced and single. The education level of cohousers in this study was quite high with the vast majority having earned graduate degrees and most of the others having completed college. Most were employed in professional occupations in fields such as education, law, architecture, medicine, and human services. The vast majority were employed full-time, while six reported part-time employment (five of whom were women with children at home), five were stayat-home mothers, and three were retirees.

\section{Great Expectations: The Four Seasons Cohousing Group}

Expectations about life in cohousing are best demonstrated by the members of the Four Seasons Cohousing Group as they were still in the planning 
process and did not yet live in an established cohousing community. I asked each one to walk me through a typical day in cohousing as they envisioned it. One indication of the centrality of shared meals to the cohousing model is their prominence in cohousers' expectations. Though no one expected common meals to happen daily, every single one of them included common dinners in their "typical" day of cohousing life. For example, one married, working mother of two described a series of activities throughout the day and concluded with: "Then we'll go to the common house with everybody else for dinner - a dinner that somebody else prepared." Her comments reveal the two most frequently stated expectations about common dinners. That is, the expectations are related to both the social and the instrumental, or labor reducing, aspects of common dinners.

There are striking gender, occupational, and parental status differences related to these expectations. In this study, single women, women without children in the home, full-time homemaking women, and all of the men (regardless of parental or occupational status) tended to emphasize the social expectations while mothers with paid employment emphasized the instrumental. The working mothers' expectations about meals were often apparent in their discussions of their instrumental motives for pursuing cohousing. They sought relief from the ongoing responsibility for family meals. In fact, some of them noted that the labor saving elements of cohousing, and especially common meals, were going to reduce their current marital strain over the issue of household labor. Nina, a working mother of a toddler, spoke frankly about the tension in her relationship over this issue:

Both Mark and I hate to cook and it's an issue for us with having kids...Cohousing is going to take some of the pressure off our marriage to divide this meal thing. I'm OK with cooking every now and then. It's the expectation that I'm going to do it every night that really gets me. So in cohousing we'll have four meals that I won't have to do so maybe the other three nights I won't feel so put upon at having to do it.

While working women were strongly attracted to the labor saving elements of common dinners, they were also attracted to the social element. Camille, a married, working mother of two, intertwined the social and the labor reducing aspects of common dinners. She expected cohousing to completely change the nature of the task. In talking about the day-to-day efforts of maintaining her family she said, "A lot of the joy that goes into something like creating a meal just gets lost. If you do have to create a meal for a bunch of other families, it's a party. You sacrifice time, but then you have other times where you might rush in at the last moment and have it fully prepared for you. It becomes a celebration!"

This component was readily recognized by many of the cohousing men. When talking specifically about the common dinners they tended to emphasize the social aspects both in terms of creating meals and consuming them with others. Men were more likely to talk about looking forward to the social activity of sharing a meal with neighbors. For example, Joel, a married father of two young boys, liked the idea of having a few meals a week with people he "found 
interesting and stimulating." For Gary, a retired, married, empty nester, the meals "would be nice to participate in for a sense of community." Men also often highlighted the social aspect of preparing the meals with other people. For example, according to Ivan, a married, working, empty nester, "Sometimes cooking feels really good when you're with other people. So if it becomes a social activity in addition to being a work task, it might actually be a social activity much more than a work task." This aspect appealed to Mark, Nina's husband, as well: "I like the fact that the project of shopping for food and maintaining the inventory and cleaning up the area and getting it prepared can't be done alone. So it is going to require people to rub up against each other and that would make it more fun!" In this light, meal preparation can lose its "work" character completely.

Although they tended to emphasize the social elements, many of the men also recognized the labor reducing element in common meals. Reducing the number of meals to be prepared in his household was important to Joel. Joel loves to cook and it's one of the domestic tasks he willingly shares with his wife, who is also a full-time professional with a demanding career. However, the constancy of the task put a damper on his enjoyment: "It would be nice not having to make dinner every night and clean up the dishes...those kinds of things like meal preparation seem like a drudgery, to tell you the truth. To me that was one of the major advantages of cohousing- shared meals."

\section{Common Meals in Practice: The Kindred Cohousing Community}

To investigate whether common meals actually meet the instrumental and social expectations of cohousers, I looked to the established Kindred Cohousing Community. Here the availability of common meals had the greatest impact in terms of meeting social needs and creating a sense of community, but the least impact in terms of meeting instrumental needs by reducing labor. An increase in the frequency of common dinners could increase their instrumental impact, but this is unlikely to happen due to a tension between communal dining opportunities and the needs of individual families for family time, especially for those families with mothers who work outside of the home.

The Kindred Community had been established for three years when I began this study. Their practice was to have common dinners two nights each week. After some experimentation early on, they settled into a team labor system to organize this and other community work. Every adult in the community is on a team. The teams operate through a five-week rotation in which each team is responsible for a different task including cooking the Monday and Wednesday night common dinners. Within each team individuals take turns being in charge of organizing each meal as the head cook. Other teammates help to plan the menu, shop for food, and then prepare and serve the meal. Setting the tables and cleaning the dining room and kitchen afterward are the responsibility of a different team that week.

On any given Monday or Wednesday about $60-70 \%$ of the community was in attendance with each household billed on a monthly basis for the number of meals they attended at a cost of $\$ 1.50$ per child and $\$ 3.50$ for each adult. This 
money is used to keep the common house pantry stocked and to purchase ingredients for future meals. The Kitchen Committee oversees the whole operation and establishes policies and procedures, such as the requirement for a vegetarian option at each meal or guidelines for cleaning the kitchen after each meal. Although there are many social benefits, the instrumental utility of the common meal system has been limited.

\section{Expectations Met: The Social Benefits of Common Meals}

Most of the Kindred cohousers described common meals as one of the best features of living in cohousing. They relish the sense of community and enjoyment they derive from preparing and sharing meals with friends and neighbors. A number of members have home-based businesses or are stay-athome moms and looked forward to interacting with others after a day in their home office or alone with children. Lee Ann is home with her two children all day and her husband often joins them for lunch. Her family goes to common dinners every Monday and Wednesday. "It's nice not to have to cook and clean as much," she told me. "It's also an opportunity to socialize which is nice... We have breakfast together and lunch together so dinner with some other people is nice." Elaine is another married, full-time homemaker who looks forward to common dinners as a chance to interact with other adults: "The meal part works really well for us, especially for me. I think a lot of people find it's too bustling at the end of a work day, but since I'm home alone a lot of the times I sort of like that level of activity. And I like seeing everybody."

\section{Expectations Unmet: The Limited Instrumental Utility of Common Meals}

The main disappointment for Kindred cohousers is the limited amount of labor and time individual households save by participating in common meals. Most reported only slight amounts of time saved due to common meals. Although this was an important expectation expressed by working mothers, they reported that common meals did not relieve their burden as much as they had hoped because Kindred holds only two common meals per week. In order to increase the instrumental value of common meals the community would need to have more of them each week. However, most people doubted that would be possible due to what they saw as the drawbacks of the common meals.

These drawbacks stem mainly from two implicit qualities of meals - the extensive invisible labor associated with them and their meaning for families in providing family time. In Feeding the Family, DeVault made visible the complexities of providing meals and the way in which doing so produces "'home' and "family"' (1991, p. 79). In a similar fashion, common meals in cohousing produce "community." However, some members feel they do so at the expense of the family. In addition, raising the meal-providing task to the community level revealed the effort and skill provisioning requires and has inhibited its expansion to the extent that it would provide significant relief for individuals and families. I will illustrate these points by examining the main drawbacks of common meals described by Kindred cohousers. 


\section{Inhibiting "Family Time"}

The Kindred members who spoke most enthusiastically about common meals and attended them most frequently were those with children. According to Lee Ann, "the core group is by and large made up of people with children. Every Monday and Wednesday we're at dinner here unless we're not in the community. And you'll find most of the people with young kids are here." Many of these parents said they would like the community to have at least one or two more common dinners a week, but at the same time they often expressed reluctance. This reluctance stemmed from the amount of extra effort more common meals would involve and the resultant decline in family time.

The incompatibility of common meals with the idea of family time is consistent with Kremer-Sadlik et al's findings regarding the definition of family dinner time as "sacred," a sacredness derived both from "intense involvement in and the isolation of" the event which is achieved by avoiding distraction and contamination by other activities (2008, p. 296). Indeed, common meals in cohousing are rife with distractions and parents in cohousing regularly described common dinners as inhibiting family time by dividing family members' attention. Children are distracted by their friends and want to get down from the table and play. Parents are distracted by their friends as well. I asked Rachel, a divorced, working mother with joint custody of her daughter Carrie, whether common dinners reduced her labor:

It hasn't for me personally...Carrie hates it...we don't get to see each other that much. And dinner - all my growing up we sat around the table and talked and visited. Can't do that down there. I can visit for about five minutes but there's somebody else who I'd rather have a conversation with or who'd rather talk with me. It's not family time. If she and I were together seven days a week, two days down there wouldn't be a big deal. But there's those two nights and another two nights I'll be out running meetings and another two nights she'll be at her dad's and that's it. So, for me, it doesn't work.

For Rachel, having joint custody exacerbates the problem of family time being reduced, but the feeling is echoed by other parents. Susan, another working mother, likes the labor reduction and thus "could live" with another common dinner night. However, in light of her husband's long work hours, she also feels that having family dinnertime is important. I asked her whether the common meals helped to reduce the effort she puts into meal preparation and clean-up:

The one big thing is that it's nice those two nights a week that I don't have to do either of those...But coming around the dinner table has always been really important to me... I think we all need to sit together quietly and have dinner. So I like the four or five nights a week we do that. I think I could live with one more night at the common house. It does make my life easier.

Susan's neighbor, Elaine, feels the same way: "I'm happy with two meals a week because it's not a family time really. It's a very social time. You get to see 
other people, but in terms of interacting with our kids, it barely happens. They want to sit with their friends or are immediately off and running with them. So I like having much more grounded family meals at home."

\section{The Challenge of Meeting Kids' Needs}

These women's experiences show that while having common meals can make life easier in some ways for them as parents of young children, there are trade-offs. In addition to the loss of family time is the added stress or labor that come as a result of feeding children in a large group setting. This was Leslie's sentiment. She's a married, stay-at-home, mother of two and was disappointed with how common meals turned out in practice. She attributes the problem, partly, to the size of the community, "It's really hard to sit down to eat with kids. It's noisy, it's stressful... When there are thirty or less people, it can be really nice. When there are sixty or seventy people it ... usually would have been just as well to stay at home."

Will, a married father of one son, experiences both the loss of family time and the additional effort related to feeding children at the common house:

We don't have these nice little quiet nuclear family meals every night... we go to the common house and that's been a challenge. We [the community] have a kid's meal, but very often Andrew can't or won't eat the kid's meals. So very often we're bringing a meal down from our house for him which means we have to cook at our house [so] half the purpose of coming down here is lost.

Although Elaine shares Will's experience she still values the extent to which common meals relieve her in terms of household labor and add variety to her family's diet:

Getting the kids to eat is the main drawback. There's just too many other fun things to do and all their friends are right there. So they sit down for a few minutes and often don't like what's being served. And so they want to get up from the table immediately and it's a battle to keep them there. Or they don't eat and we come home and feed them cereal at 7:30. So, the actual meal part doesn't work very well for the kids. Socially, they love it but they don't eat a whole lot down there. But I love it.

Do you find then that it's not really a labor saving device for you?

Oh, it definitely is because it's easier to fix them a bowl of cereal than to cook a whole meal for all four of us. No, it definitely is.

\section{Barriers to Increasing the Instrumental Utility of Common Meals: Family Time and the Labor of Communal Provisioning}

Adding more meals would theoretically reduce the workload associated with meals for individual households, but as noted above, some were reluctant to sacrifice family time any further than the current two nights a week. Others were averse to adding more nights due to the increase in community level work. Take 
Joanne, a married, working mother of one, for example: "I wish it was dinner in the common house five nights a week because I don't like to cook. But on the other hand I don't want to be the person who has to put in more time cooking."

As stated earlier, raising the meal-providing task to the community level reveals, and somewhat increases, the effort and skill it requires. This, in turn, inhibits its expansion to the extent that it would provide significant relief for individuals and families. The following statement, made by Joseph, a married father of one, illustrates this point:

We've been less successful at having as many meals as we want because it takes a lot of work to cook for thirty or forty people... So we have a couple of nights. If we were a smaller community, it might happen more spontaneously. We might all just gather at 5:30 and figure out what to make for dinner if we were only ten households. Maybe, I don't know.

Though he expresses doubt, Joseph seems to believe that with a smaller group meals could happen spontaneously. But he doesn't acknowledge the amount of advance effort required whether one is feeding a group of three or a group of thirty. Joseph's thought that ten families could gather at 5:30 in the evening and "figure out" what to make for dinner demonstrates the invisibility of the mental and physical processes which lead up to meal preparation. Although I am sure he was well aware that menus must be planned and groceries bought, he seemed to be separating them from the act of "making" dinner, probably because these are tasks usually done at another time and usually, he reported, by his wife.

Like Joseph, Kevin (married, but not a parent) also believed that it would be easier to have more meals in a smaller community. He was one of a number of cohousers who wished there were more dinners at Kindred. When I asked him why there weren't, he replied, "it takes a lot to cook for anywhere from forty to eighty people and it's a big job. It takes several people to clean up for an hour and a half to two hours afterwards. I think in smaller communities they can have more meals because meal preparation is not a big issue. You cook and eat and clean up in about an hour - all the dishes for a meal fit in one dishwasher."

Although Joseph, Kevin, and others believed more common meals would be possible in a smaller community, this is not likely. Family time would remain an issue and in a smaller community there would be fewer people among whom to divide the work. In fact, the larger the community, the easier it should be to have more common meals than two per week. However, the work of common meals is perceived by some cohousers to be more cumbersome than the work of homebased meals, and to some extent it is.

\section{Home-Based vs. Communal Meals}

In individual households women tend to be primarily responsible for the planning and coordination involved in "feeding work," as well as "the constant juggling and strategizing behind the physical work" (DeVault, 1991, p. 56). According to DeVault, "the invisibility of this thought work, along with the way it combines with physical tasks, can hide this part of housework even from those who do it" because it is often "squeezed into the interstices of other activities" 
(1991, pp. 56-57). So in preparation for a home-based meal a woman might plan a menu while driving home from work, for example. But in cohousing common meals are a group effort and time must be set aside to meet with teammates for meal planning, posting menus, shopping, preparation, set-up and clean-up.

In cohousing there are additional tasks related to meals. Someone has to keep track of the billing and payments. Holly, a working, married mother of one, is one of those people. "I spend about an hour and a half a month helping somebody that does billing for meals. We get all these meal sheets. For every meal there's a set of sheets. So that might be ten sheets a month. And I go through and tally, for everybody in the community, how many meals they went to so the bills can get put out."

In addition to the coordination and added tasks associated with meals in cohousing, different skills are needed to plan a meal for four than to plan and accomplish a meal for forty. Joanne raised that point: "I think we'll increase the days as we learn how to make menus that are simpler and people become more comfortable in the kitchen. Different people are willing to be head cook. In the first year or so only those who really enjoyed cooking were the head cooks."

As Joanne indicated, not everyone feels comfortable in the head cook position. And there is no pressure on people to take that role. As Clara, a retired, divorced, empty nester told me, "I've been cooking for years and I really enjoy cooking, but I find cooking for sixty, seventy, eighty people very stressful. And I don't need stress in my life. So I just decided I wouldn't do that. I help other people cook." Bridget, a working, single woman whose grown daughter and young grandchild resided with her, explained to me how the system accommodates different task preferences: "It's set up with an expectation that everyone does everything within a negotiating frame. You're on a team with a random selection of other people and you have certain tasks to do and you work it out among your team. For instance, I hate cooking. I don't do it. You know, I'll chop vegetables or something but I won't be the head cook or in charge of a meal or anything." Interestingly, the division of labor around communal meals at the common house appears to be equally shared among men and women. As Joanne shared, "Men are as involved in putting that meal together as anybody...We have many men here who are great cooks, which really in my own sexist way of thinking was a surprise to me. There are many men who cook here and love doing it."

Another critical difference between home-based cooking and communal cooking is that in cohousing the distribution of the work must be managed among a team whereas family meals are typically the sole responsibility of one person (usually a wife and/or mother) who may or may not delegate and supervise some portion of the physical tasks. Above Bridget described negotiating with other team members to distribute the work, but before the team system was implemented the distribution of labor was unequal and there was no way to balance it. According to Melissa, it was not necessarily the case that people were avoiding the work, but that they didn't know what needed to be done: "We developed [the team system] after we realized there were some folks who were putting in a whole lot of hours and work and other folks who were not and there 
was some resentment coming up around that. We wanted to figure out a way to make it fairer so that everybody was participating and make it easier for those folks who had a difficult time finding where they fit in."

Before the team system was established, it was more difficult for people to determine whether they were doing their "fair share." Amelia, a married, parttime working mother of two, described what it was like before there was a structure in place for meal preparation and clean-up:

Around the meals it was all voluntary. So lots of people would volunteer to cook because they liked to cook, but not that many people volunteered to clean. It wasn't so much that you couldn't get people to clean when you made an announcement during dinner. But you'd have to interrupt dinner to make that announcement. And then you'd have to sit there at dinner going, "Well, did I do my fair share? I don't really want to volunteer."

The team system helped make the distribution of the work more visible and fairer. Finally, below the surface of the home vs. communal issue is an important question regarding gender and household labor.

\section{Do Communal Meals Help Balance Household Labor by Gender?}

In addition to the social and instrumental outcomes of common meals I wanted to assess their contribution to balancing household labor by gender. This question has two components. One, is there gender balance in the work of the community, particularly with regard to meals? Two, do common meals help balance by gender the division of labor within individual families by redistributing some of the work to the community? The answer to the first question is yes and the answer to the second one, at least in the case of this cohousing community, is no.

It was my expectation that by transferring some of the labor of individual households to the purview of the community that cohousing would help to balance household labor by gender. This was based on the idea that the work of the community would be contributed to equally by the members of each household. Where one spouse may have previously been solely responsible for a task (like meal preparation), its transfer to the community level would also transfer half of the responsibility for the task to each spouse. This would reduce the absolute amount of individual household labor and divide the communal work evenly between spouses resulting in more overall balance by gender. However, in terms of balancing the individual household work associated with meals by gender, Kindred Cohousing falls short.

Whether they had a traditional or more egalitarian division of labor in their household, none of the couples in this study reported a change in their arrangement after moving into cohousing. The cohousing structure itself neither helped nor hindered the efforts of couples toward egalitarian arrangements. While it may have decreased the amount of labor required in each individual household by communalizing some of the work, it has done so only slightly and it has had little or no impact on the work that is not communalized. While partners appeared to share equally in the team rotation for the two weekly common dinners, for the 
most part women were still primarily responsible for meals the other five nights at home. So in that way the division of labor within individual households tended to remain unbalanced.

If the Kindred Community had more common meals each week, there could be a greater impact in terms of shifting the workload and redistributing it within families. That would depend, of course, on equal participation in communalized work. And indeed I did find that overall the work of the community was more balanced by gender. This balance was attributed to the team system. In a discussion about community work participation Amelia said, "I'm much more comfortable with it now that we've gone to the teams. There's more accountability. It used to be that certain people cleaned the common house and certain people mowed the lawns and it was much more divided probably by sex. And now it's spread out more." Joanne also reported greater gender balance in the team system: "Everybody on your team is given a job and that's the place I see the most combinations of men and women working together." She noted this balance both in the cooking and the common house cleaning. "But," she added, "men don't immediately volunteer to clean the bathrooms and the toilets." This observation by Joanne suggests that subtle gender dynamics with regard to negotiating the distribution of tasks may be at work. Yet, the overall pattern in the interviews indicated a general feeling of gender balance in communal labor among both men and women.

While there appeared to be a fairly good gender balance in the community work done by teams, I also wondered whether there was an equal contribution to teams by both partners within each couple. The team system was relatively new to the community and it was in its second configuration. The majority of couples with children had been on different teams in the first configuration so that one partner would always be free to be home doing child care. Most couples also chose to be on different teams in an effort to get to know more of the other community members better. One effect of that arrangement was that the individuals in each couple were responsible to separate teams, but when the community reorganized the membership of the work teams all of the couples opted to be on the same teams, mainly due to busy family schedules. I suspected this would lead to an imbalance within couples in terms of their team responsibilities, with one partner doing more of the couple's share of team labor. But in fact, although there was some slight variation between and within couples, there seemed to be a general sense of balance. Susan explained the switch in team membership:

We're on the same team and fortunately we both have a similar approach which is we uphold our end of the deal. We might not always like the team activity or responsibility but we're going to it. We don't want to clean the Common House on Saturday morning but we're all going to show up. And I guess if there's a thing that requires one of us to be with the kids or something, Jeff and I are pretty equal about who's going to do it.

Just about everyone said they divided the team duties about equally. There may be an additional force at work in terms of the balance of team labor within 
couples. When the new team rotation was established it brought the division of labor within couples into the public eye. The way each couple divided their contribution to team efforts became visible to other members of the team. This visibility may have an influence on the couple in that each partner might wish to be perceived as doing his or her fair share. Thus, the community level gender balance may be partly the result of a subtle form of peer pressure.

\section{Conclusion}

A growing body of literature on food and culture, what Sherry Inness (2001) refers to as "kitchen culture," is critically examining the connections among food, meal preparation and gender in families. However, little attention has been paid to those who are experimenting with alternatives to mainstream family structures, including communal lifestyles, where shared meals play a vital role for most groups. This article is an attempt to begin to fill in that gap by exploring the tension between the notion of the family dinner as family time and the opportunity for redistributing, and balancing by gender, mealtime household labor in cohousing.

I began by exploring the extent to which common meals met cohousers' social and instrumental expectations for increased social activity and decreased household labor. I found that common meals do a good job of meeting the social needs emphasized by male cohousers, women without children at home, and stayat-home moms. However, they do not go very far toward meeting the instrumental needs emphasized by working mothers. At Kindred, with just two dinners per week, they are only slightly reducing the work done in individual households for meals and not really balancing that work by gender except in the case of community dinners. The solution - an increase in the number of community meals - is hindered by the effort and skill required to prepare meals for large groups of people. This could be addressed by creating smaller groups within the community for meal sharing. For example, the community could be divided into two groups with each group having common meals on alternate nights of the week. Each group would have fewer people making for easier preparations and fewer distractions for family members.

The most significant barrier to realizing communal dining's potential for greater gender balance in household labor was the second focus of this study - the tension between community meal participation and the desire for family time within nuclear families. Despite being the most dedicated attendees at common meals and, in the case of the working mothers, those with the highest expectations for their potential to lighten the family workload, the parents with children at home were very reluctant to increase the number of community meals in favor of maintaining private family dinner time most of the week.

Given the extensive efforts involved in cohousing (projects typically take several years of intensive work to bring them to fruition and require many monthly hours of community work and meetings thereafter), a structure most were attracted to at least in part to support their parenting, it appears highly ironic that they would withdraw from or limit their participation in a key feature of the model in practice. Yet, the cultural pressure for "family time" and the relative 
absence of cultural norms valuing communal practices, serve as powerful explanations. In a comparative study of cultural ideologies regarding family time, Kremer-Sadlik et al (2008) found American parents sharply delineating family time for only immediate family members in contrast to Italian families who readily included friends and even work associates. As Gutierrez et al found, "family dinner is viewed as a priority family project fundamental to the identity of the family, but often at odds with individual and other relational identity projects" (2008, p.189). The wider community, intentional or otherwise, is but one of many competing "identity projects."

Indeed, this tension between the nuclear family and the larger community has a long history in communal movements, from the Israeli kibbutzim to the $19^{\text {th }}$ century Oneida Community to the so-called hippie communes of the 1960s and '70s. Though the family time issue might be addressed in this case by a solution as simple as allowing families to pick up dinner at the common house to take home and consume privately, other historical examples indicate this would likely create cohesion-related tensions within the community. The family time dilemma is likely to remain for cohousing families without a shift in values placing higher priority on communal identity and experience above that of the nuclear family. This is unlikely to occur given the appeal of the cohousing model as a bridge between "two concepts: home as private sanctuary from the outside world versus home as a place rooted in a comforting web of relationships in a place-based community" (Lindemann, 2000, p.45).

Finally, I analyzed the extent to which communalizing meals helped to redistribute and balance household labor by gender. Despite the minimal impact of communalizing meals in the Kindred Cohousing Community, the findings suggest that this strategy does have potential for addressing both the volume and distribution of household labor for both cohousing families and those living in mainstream housing. For cohousing families, an increase in the frequency of common meals would decrease individual household labor and increase the more gender-balanced communal labor. In fact, many cohousing communities in the U.S. and most of those in Denmark (the home of the cohousing model) share common meals as many as four or five times per week (McCamant and Durrett, 1994).

For families living in non-communal, mainstream housing there are other possible mechanisms for communalizing the labor associated with meals (apart from the now-popular, yet cost-prohibitive restaurants and take-out) with varying impacts on the family dinner time. One example is the dinner cooperative in which a small group of households takes turns cooking for each other (Hochman, 1994; Shaffer and Anundsen, 1993). It might be a weekly meal at rotating houses or a less social, more practical arrangement in which members take turns cooking one or more nights per week for others who simply stop in to pick up their food and return home for their own family time. These and other strategies bear further investigation, both by families seeking a better balance between home and work demands and the researchers interested in them. 


\section{Acknowledgments}

This research was supported by The Initiatives for Women Fund (The University at Albany) and the Dr. Nuala McGann Drescher Affirmative Action/Diversity Leave Program (United University Professionals and SUNY Potsdam). The author wishes to thank the editor and anonymous reviewers for their careful reading and very helpful feedback on previous versions of this article.

\section{References}

Ahrentzen, S. (1996). Housing alternatives for new forms of households. In G. C. Hemmens, C. J. Hoch, \& J. Carp (Eds.), Under one roof: issues and innovations in shared housing (pp. 42-62). Albany: State University of New York Press.

Bose, C. E. (1979). Technology and changes in the division of labor in the American home. Women's Studies International Quarterly, 2(2), 295-304.

Davidson, R., \& Gauthier, A.H. (2010). A cross-national multi-level study of family meals. International Journal of Comparative Sociology 51 (5), 349-365.

DeVault, M. L. (1991). Feeding the family: The social organization of caring as gendered work. Chicago: University of Chicago Press. . (1997). Conflict and deference. In C. Counihan, \& P. Van Esterik (Eds.) Food and culture: A reader (pp. 240-258). New York: Routledge. . (2000) Producing family time: Practices of leisure activity beyond the home. Qualitative Sociology, 23(4), 485-503.

Endrijonas, E. (2001). Processed foods from scratch: Cooking for a family in the 1950s. In S. Inness (Ed.), Kitchen culture in America (pp. 157-174). Philadelphia: University of Pennsylvania Press.

Gutierrez, K., Price, L.L., \& Arnould, E. J. (2008). Consuming family dinner time. Advances in consumer research. 35, 189-193.

Hayden, D. (1984). Redesigning the American dream: The future of housing, work and family life. New York: W. W. Norton \& Co.

Hochman, A. (1994). Everyday acts \& small subversions: Women reinventing family, community and home. Portland, OR: The Eighth Mountain Press.

Hochschild, A. (1997). The time bind. When work becomes home and home becomes work. New York: Metropolitan.

Inness, S. (2001). Kitchen culture in America. Philadelphia: University of Pennsylvania Press.

Kremer-Sadlik, T., Fatigante, T., \& Fasulo, A. (2008). Discourses on family time: The cultural interpretation of family togetherness in Los Angeles and Rome. Ethos, 36(3), 283-309.

\& Paugh, A. L. (2007). Everyday moments: Finding 'quality time' in American working families. Time Society, 16(2/3), 287-308.

Larson, R., \& Richards, M. (1994). Divergent Realities: The emotional lives of mothers, fathers, and adolescents. New York: Basic Books.

Laslett, B. (1973). The family as a public and private institution: An historical perspective. Journal of marriage and family, 35, 840-492. 
Lindemann, D. (2000). Cohousing. In Communities directory: A guide to intentional communities and cooperative living. Rutledge, MO: Fellowship for Intentional Community.

McCamant, K. \& Durrett, C. (1994). Cohousing: A Contemporary Approach to Housing Ourselves ( $2^{\text {nd }}$ edition). Berkeley, CA: Ten Speed Press.

Meltzer, G. (2005). Sustainable community: Learning from the cohousing model. USA: Trafford.

Neuhaus, J. (2001). The joy of sex instruction: Women and cooking in marital sex manuals. In S. Inness, (Ed.), Kitchen culture in America (pp. 95-118). Philadelphia: University of Pennsylvania Press.

Parkin, K. (2001). Campbell's soup and the long shelf life of traditional gender roles. In S. Inness (Ed.), Kitchen culture in America (pp. 51-68). Philadelphia: University of Pennsylvania Press.

Price, L. (2008). Doing family: The temporal and spatial structuring of family consumption. Advances in consumer research. 35, 189-193.

Reinharz, S. (1992). Feminist methods in social research. New York: Oxford University Press.

Shaffer, C. R., \& Anundsen, K. (1993). Creating community anywhere: Finding support and connection in a fragmented world. New York: Tarcher/Perigee Books.

Schor, J. (2005). Work, family and children's consumer culture. In J. Heymann, \& C. Beem (Eds.), Unfinished work: Building equality and democracy in an era of working families (pp. 285-305). New York: The New Press.

Spain, D. (1992). Gendered spaces. Chapel Hill, NC: University of North Carolina Press.

Spitze, G. and Loscocco, K. (2000). The labor of Sisyphus? Women's and men's reactions to housework. Social science quarterly, 81(4), 1087-1100.

Sullivan, O. (2010). Men's changing contribution to family work. In B. Risman (Ed.), Families as they really are (pp.393-401). New York: WW Norton \& Co.

Sullivan-Catlin, Heather. (2004). "A good borderland": Cohousing communities and social change." Communal studies, 24, 119-139.

Weiss, R. S. (1994). Learning from strangers: The art and method of qualitative interview studies. New York: The Free Press.

\footnotetext{
${ }^{\mathrm{i}}$ The Cohousing Association of the United States: www.cohousing.org

ii All community and individual names are pseudonyms adopted to protect confidentiality.
} 